\title{
Strategic Facilities Planning: A Focus On Health Care
}

\author{
Ellen D. Hoadley, Loyola University Maryland, USA \\ Brian Jorgensen, McCormick \& Company, USA \\ Craig Masters, Navigant Consulting, USA \\ Nalli Tuma, Dentsply Professional, USA \\ Scott Wulff, Becton Dickinson Diagnostic Systems, USA
}

\begin{abstract}
Turbulent market conditions have forced the health care sector to re-examine its business and operational practices. Health care has become increasingly complex as decisions and planning are reframed in light of the current lagging economy, an increased demand for services, new global competition, and impending legislation reform. The stress is felt most keenly within the nation's hospitals and consortia of health care facilities. Facility planning decisions are no exception. Hospital administrators are abandoning the once commonplace rules governing aging infrastructure renovations. Instead, administrators are basing decisions within their respective strategic context and are attempting to align buildings, services, personnel, and technology to an overall plan that looks at markets, operations, and finances as resources for competitive advantage. This paper reviews the strategic facilities planning literature and applies those best practices which support this organizational alignment for health care. An application in the midAtlantic demonstrates that hospital facilities, by design, need to support the current and future needs of health care delivery systems, while dated structures impede industry advances. Health care infrastructure improvements must proactively address technological, regulatory, and financial changes facing the sector.
\end{abstract}

Keywords: health care, facilities, strategic facilities planning, space utilization

\section{STRATEGIC FACILITIES PLANNING OVERVIEW}

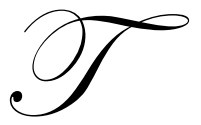

he International Facility Management Association defines a strategic facility plan (SFP) as a two-tofive year plan that comprehensively articulates the type, quantity, and location of spaces required to support an organization's business objectives (__ b, 2009). The overall plan then prioritizes shortterm plans and funding to achieve those business objectives. The goal is to ensure the strategic functionality of the physical environment through the integration of people, places, processes, and technology (__ a, 2009). While incorporating an enterprise-wide perspective, SFPs also are flexible and living documents that implement long-term goals through data-driven tactics such as relocations, downsizing, mergers and acquisitions, new construction, renovation, site and facility selection, and real estate decisions. Such plans incorporate multiple factors such as the current business mission, future vision, current facilities base, and projects currently underway. In doing so, they gain organizational support and credibility internally and externally while strengthening the competitive position and performance. To gain these benefits, organizations use a step-by-step process of understanding, analysis, planning, and acting (Glagola, 2002).

The International Facility Management Association b, 2009) has further defined the SFP process steps as:

1. Understanding the organization's mission, vision, value and goals through four key measurements: financial performance, customer knowledge, internal business processes, and learning. 
2. Analyzing the organization with techniques such as SWOT and/or scenario planning to explore the potential future outcomes.

3. Planning that encompasses the long-term and annual needs of the organization.

4. Acting to implement the plans while collecting feedback as to the products and processes.

\section{HEALTH CARE YESTERDAY AND TODAY: THE CONTEXT}

The current competitive environment for health care competition is fierce. Approximately 5,000 acute care hospitals in the United States compete for their 30\% share of \$2.4 trillion spent for health care. This yields an overall market of $\$ 720$ billion (Keehan et al., 2008) Ancillary competition is increasing from independent physician practices, medical tourism, and alternative medicine. Yet patient volume growth, supported by forecasted US demographic predictions, is perceived as the primary method for sustaining growth. Because patients have many options, hospitals know they must also improve their marketing efforts while sustaining these efforts by meeting customer expectations, introducing new technologies and programs, and building facilities.

Traditional market competition has failed to produce quality and cost improvements in health care, resulting in current efforts to reform the industry (Porter and Teisberg, 2004). Impending legislation and increasing pressure on cost structures have driven health care administrators to examine both positive and adverse outcomes from industry competition. Porter and Teisberg (2004) posit that in the past, the objective of health care improvement was to reduce and avoid costs - through increased bargaining power and rationing. The authors contend that in the current environment, the objective for improvement is to enable choice - through endorsed health plan options. Endorsement requires that errors be reduced. By focusing on improved provider and hospital practices, through process innovation and redesign, health care is learning that doing things right the first time improves outcomes and can also cut costs.

Strategically, to achieve improved outcomes and cost reductions, the trend in the industry has been for health care facilities to move to specialization. Procedure specialization has resulted in an accelerated learning curve due to the resulting economies of scale for the facility. This learning creates better outcomes as measured by lower mortality rates. These outcomes are maximized through continual process improvement (Porter and Teisberg, 2004). It is in this area of process improvement that health care providers are examining their facilities to determine how more strategic facility planning can contribute to improving economic circumstances for themselves and the industry as a whole.

Process improvement for health care must occur within an existing context of financial realities and external regulation. These factors have contributed to the shift from cost reduction to process improvement driven competitive strategies. The shift in these factors has evolved over the past 40 years based on changes in regulations, reimbursement policies, percentage of total cost paid by the patient, the mix of inpatient vs. outpatient procedures, and the overall percentage of health care costs that can be attributed to hospitals (see Table 1) (_, 2008). The industry's service delivery has shifted; fewer inpatient procedures are delivered as compared to outpatient procedures, yielding a lower percentage of health care costs accounted for in hospital facility revenues. These are the financial realities driving hospitals to examine their facilities management strategically. The questions become

1. If more outpatient procedures are delivered and fewer dollars are available to hospitals, what are the most cost effective procedures for any particular hospital to provide?

2. How do integrated health care delivery systems (that include hospitals) continue to compete with smaller niche facilities that skim the most lucrative procedure dollars?

3. How do hospitals with aging facilities and infrastructure continue to attract patients who have access to newer facilities?

4. How do hospitals with unused or underutilized facilities and infrastructure hold or increase their return on facility assets? 


\begin{tabular}{|c|c|c|c|c|c|}
\hline \multicolumn{7}{|c|}{ Health Care Competitive Cost Factors Changing over Time } \\
\hline Decade & Regulations & Reimbursement & Payers/Consumers & $\begin{array}{c}\text { Inpatient/ } \\
\text { Outpatient }\end{array}$ & $\begin{array}{c}\text { Hospital \% of } \\
\text { Health care \$ }\end{array}$ \\
\hline$<1970 \mathrm{~s}$ & Hill Burton & Cost based & $\begin{array}{c}20 \% \\
\text { patient cost sharing }\end{array}$ & $\begin{array}{c}95 \% \text { IP } \\
5 \% \text { OP }\end{array}$ & $50 \%$ \\
\hline \multirow{2}{*}{$1980 \mathrm{~s}$} & $\mathrm{CON}$ & $\begin{array}{c}\text { Prospective Payments } \\
\text { (DRGs) }\end{array}$ & $\begin{array}{c}10-15 \% \\
\text { patient cost sharing }\end{array}$ & $\begin{array}{c}85 \% \text { IP } \\
15 \% \text { OP }\end{array}$ & $40 \%$ \\
\hline $1990 \mathrm{~s}$ & CON repeal & $\begin{array}{c}\text { Balanced Budget } \\
\text { Act I }\end{array}$ & $\begin{array}{c}10 \% \\
\text { patient cost sharing }\end{array}$ & $\begin{array}{c}50 \% \text { IP } \\
50 \%\end{array}$ & $35 \%$ \\
\hline $2000 \mathrm{~s}$ & DOJ/FTC & $\begin{array}{c}15-20 \% \\
\text { palanced Budget } \\
\text { Act II }\end{array}$ & $\begin{array}{c}30 \% \text { IP } \\
70 \% \text { OP }\end{array}$ & $30 \%$ \\
\hline
\end{tabular}

It is these questions that have moved health care facilities to undertake strategic facility planning (Reeve 2001). The next question is if health care facilities choose to undertake such planning, what best practices can they use or incorporate to have the most positive outcomes? What can health care learn from other industries who have undergone the same shift?

\section{TECHNOLOGY INTERVENTIONS: THE ENABLERS}

Historically, technology has been a key enabler of process redesign. This reality is emerging in health care in the application of smart patient rooms and electronic medical records. The improvement takes the form of accurate and reliable information captured, stored, retrieved, and displayed to enable timely and effective decision making. More specifically, smart rooms provide bedside access to timely patient information by caregivers as well as patients themselves. Voice recognition and laser pointers improve patient outcomes by reducing or eliminating direct contact with work surfaces. Caregiver data entry improves the timeliness and accuracy of patient information capture. Patient safety and security updates can be provided at the room and/or bedside. , 2008)

The smart rooms are connected to a technology center that performs the command center role in decision making. Just-in-time data provides support for collaborative decision making and action and removes the fragmenting of care processes around traditional hospital departments. Modeled after the military or air traffic command center, such patient care command centers provide real time clinical, operational, and logistical information for staff and physicians, notify departments of patient readiness for procedures and treatments, controls the timing of patient flow through the facility which decreases downtime and increases efficiencies, monitors activities to predict patient flows, and increases staff and customer service. 2008)

Technology enables the global sharing of medical information across providers and locations - allowing each patient to receive a data-driven analysis, prognosis, and treatment plan - no matter where the patient is treated. This reality supports the transition of care away from the hospital to any number of ancillary health care facilities and into homes through telehealth applications. For this reason, it is even more important for hospitals to use technology to provide the highest standard of medical care ( , 2008)

\section{THE STRATEGIC HOSPITAL FACILITY PLAN：UNDERSTANDING}

Given SFP practices, hospital requirements, and technology opportunities, what steps does the hospital administration take to develop a strategic hospital facility plan? The three components include market analysis, operational review, and financial feasibility. The planning process must answer the following:

\section{Market analysis}

1. How will the hospital accommodate projected demand in its primary service area as well as the greater region?

2. What service area has an increasing market share? Declining?

3. What are the population and demographic trends in the primary service area and greater region? 
4. Who are the employers and insurers in the primary service area and greater region? What are their capacities?

5. Does the hospital have the necessary physicians? If not, what is the plan to recruit and retain the necessary physicians?

\section{Operational review}

1. How big should the facility be in 10 years? 20 years?

2. How can efficiency be maximized in throughput and resource usage?

3. How can space support highly efficient operations?

4. How can technology improve operational decision making?

\section{Financial feasibility}

1. Can our organization afford to invest in our facilities?

2. Will our service lines be profitable enough to support a major construction/renovation project?

3. What start-up costs would be required? Is there enough capital to cover the start-up prior to realizing the revenues of the plan?

Yet the most important question to consider is: Does this plan or project support the organization's mission?

\section{CURRENT FACILITY MAINTENANCE: ANALYZING}

Shohet (2006) extended strategic health care facilities management to include maintenance of those facilities as well. His key performance indicators for determining optimal planning for maintenance include

1. Asset development

a. Built area size

b. Occupancy

c. Age

2. Organization management

a. Number of employees per $1000 \mathrm{~m}^{2}$ built area

b. Scope of maintenance outsourcing

c. Maintenance supervisory span of control

d. Maintenance organizational structure

3. Performance management

a. Building performance indicator based on the level of safe and appropriate performance of the building's components

4. Maintenance efficiency

a. Annual maintenance expenditures per square meter

b. Annual maintenance expenditure per patient bed

c. Maintenance efficiency indicator (maintenance expenditure relative to age)

\section{A CASE STUDY FROM MARYLAND}

Holy Cross Hospital in Silver Spring, Maryland, is engaged in a planning project that incorporates the process described here. They initially engaged in a market analysis that incorporated current and future hospitals of their own and competitor groups. Using a geographic information system (GIS), they plotted the location of the region's health care facilities along with major highways and transportation systems. Next they added the location of all physician office locations including specialty and number of physicians per office. Once the geographic market space was analyzed, they used the following tools and technologies to determine what the future facility plan should be: 
1. Systematic layout planning to create conceptual block layouts

2. $\quad$ SWOT analysis

3. Organizational simulation to visual flow through the facility plan

4. Capacity models approximating production, utilization, seasonality, and throughput

5. Utilization analysis of departments

6. Benchmarking with peer groups

Holy Cross recognized the constraint from the financial feasibility plan of a limited revenue stream to manage the high fixed costs of the proposed facility. They chose instead to exploit the constraint by determining the best way to draw profitable patient volumes while optimizing resources, reducing wait times by expediting care through bottlenecks, and increasing patient satisfaction. They then made the final decision for the capital plan based on return on investment.

\section{LESSONS TO BE LEARNED: PLANNING}

The planning process is ongoing. Through the process, the Holy Cross facility planning group is heeding the following to create the optimal plan (Weitzner, 2006):

1. Solve systems, not problems.

a. Adding space solves a problem temporarily; the return is better when the system is fixed permanently.

b. Communication and collaboration with the actual facility users is essential; the wisdom and buy-in of the human capital can make or break the plan.

2. Focus on real population needs, not perceived needs.

a. Avoid the "field of dreams" mentality, because they may not come.

b. New facilities will not change the usage rates of current populations.

c. Use data and sensitivity analyses to determine ultimate facility requirements.

3. Be accurate, not precise.

a. Data is great, but it can be distracting.

b. Facility and space requirements are not the same as financial reporting. Beds typically fill the overall space provided in blocks that are accurate \pm 30 , so a projection of 280 beds versus 300 beds will likely result in the same yield in the end.

4. Room size doesn't matter, but quantity does.

a. There is a temptation to focus on reducing the size of rooms to save on capital costs; however the number of rooms drives the costs of equipping those rooms.

b. The quantity of rooms is based on critical forecast and through-put assumptions.

5. Focus on function over preference.

a. The plan should be driven by the goals and critical success factors of the organization. Keep those uppermost in the planning process and communications.

b. Use the critical success factors to audit the layout options.

In the end, the potential exists to over plan as well. The SFP process must retain an iterative improvement process because according to Wendy M. Weitzner of Kaiser-Permanente, "No amount of good planning will result in a perfect building that will meet all needs for the next 50 years." The strength of the strategic planning model is its ability to support best health care practices and the process enablement of state-of-the-art technology while allowing for the integration of advances over time using a more evolutionary approach."

\section{BEST PRACTICES: ACTING}

For more than 50 years, The Joint Commission on the Accreditation of Healthcare Organizations (JCAHO) has worked to improve the quality and safety of health care services. Today, it is the largest accrediting body of health care organizations in the United States, accrediting and certifying more than 17,000 health care organizations. It is recognized as a leader in all aspects of safe, high quality care. In 2006, JCAHO produced a report that articulates the roadmap for developing the hospital of the future ( , 2006). The commission reports on these principles specifically for hospital facility planning. 
1. Design safety in from the beginning

Existing facilities have persistent problems that must be recognized and mitigated through data-driven design. These include safety issues, hospital-acquired infection, and worker fatigue. New hospitals will increasingly serve elderly patients who will require facilities designed to safely accommodate them.

Additionally, threats to patient safety such as medication errors, falls, and transfer errors can also be minimized through strategic planning that increases lighting, reduces noise, provides visibility of patients to the nursing staff.

2. Learn the lessons of the flat world phenomena

In the global economy, people travel more; the supply chain is global; the media provide awareness of global disasters. The flat world lends itself to the global spread of disease, to the assistance in recovery of disasters, and to the potential disruption of pharmaceutical supply chains. Hospitals require planning for expansion and reduction of capacity within the physical environment to accommodate the flattened world.

3. Embrace standardized flexibility

The manufacturing sector is building flexibility into its operational processes. Hospitals must likewise build in flexibility. However, unlike in the manufacturing environment, such flexibility comes through standardization of rooms, equipment, and processes. Such design reduces the costs of disruptions by providing a consistent context for varying process pieces to occur in varying and often unpredictable sequences and frequencies.

4. Provide as much safety for hospital employees as for patients and families.

Design facilities to move supplies closer to their intended usages to reduce travel and walk time for care givers. Use ergonomic technologies to reduce heavy lifting, transporting, and turning of patients. Beyond increasing safety, such designs contribute to a culture of safety that benefits all who enter the facility.

5. Design for sustainability and healthy living spaces.

Historically, hospitals have not been environmentally friendly. Chemicals have been used in hospital building supplies and medical supplies; hospital emissions have created toxic spaces for patients and health care workers. What does it say about a facility that treats disease and infection while simultaneously degrading the air and material quality of that space? In addition, hospitals should be designed to be energy efficient with low carbon footprints and high percentages of recycled materials. Food served should promote wellness using healthy ingredients that are local, humane, and environmentally protective.

Holy Cross Hospital's facility planning group is applying the best practice principles to create a sequence of action plans that realize the following operational implications.

1. Consolidate flows

a. Organize operations and spaces around like experiences.

b. Deploy resources to the point of use; minimize patient movements.

c. Aggregate "outpatients-in-beds" to universal care unit.

d. Design to the frequent; respect the few.

2. Standardize care spaces

a. Increase safety and minimize risk.

b. Focus on information flow that is timely, accurate, relevant, and coordinated.

3. Base decisions on current data

a. Use real time metrics.

b. Enforce transparency of decision making with data. 
4. Plan for transformation

a. Recognize that transformation is essential to realizing hospital goals.

b. Address the consequences of misguided incentives.

There is still much to learn in the application of facilities planning concepts to hospital facility planning. It's a bit like trying to change the tires on a moving bus; the context, competitive environment, customer needs and technology enablers are all changing at an increasingly rapid rate. Hospital planners, who get it right the first time, stand to realize strong gains. The 2009 Community Health Replacement Study (__ c, 2009) reports on the operating performance of replacement hospitals using the financial metric of Earnings before Interest, Taxes, Depreciation, and Amortization (EBITDA). The replacement hospitals studied over a 7 year period realized a declining EBITDA in the years prior and during replacement followed by substantial gains in the years following replacement. The same improvement trends were reported in median operating margins, and median debt to cash flow. These financial improvements were the results of improved staffing and throughput rations that were realized in the strategically developed facilities. Those hospitals which use the guiding principles above translated into operational and tactical plans for development have the highest opportunities to remain competitive.

\section{AUTHOR INFORMATION}

Ellen D. Hoadley, Ph. D., is Professor of Management Information Systems at Loyola University Maryland where she has taught since 1988. Dr. Hoadley teaches Information Technology and Strategy and Operations Management in the MBA and Executive MBA programs, as well as Systems Analysis and Design at the undergraduate level. Her research areas include business process reengineering, requirements determination in systems analysis, and the use of color in the human/computer interface. Dr. Hoadley has published in journals such as Communications of the ACM, Journal of Business and Economic Perspectives, and Journal of Knowledge and Process Management.

Brian Jorgensen is currently an Associate Product Manager with Simply Asia Foods, a division of McCormick \& Company. In his current role, Brian is responsible for developing and executing a new item pipeline strategy that will allow Simply Asia Foods to continually increase revenues by capitalizing on the emerging and evolving consumer demand for Asian cuisine. Brian has completed his MBA from Loyola University Maryland.

Craig Masters has fifteen years of healthcare finance experience including capital planning, strategic analysis and decision support for providers ranging from large integrated health systems to rural critical access hospitals. He also has significant experience in hospital/physician integration and reimbursement policy. Craig is a licensed Certified Public Accountant, a Fellow in the Healthcare Financial Management Association, and a Loyola University Maryland MBA.

Nalli Tuma is an International Marketing and Product Manager for Dentsply Pharmaceutical, a division of Dentsply International, located in York, PA. Nalli, originally from Brazil, has been in the US since 1998. She has a BA in Economics from PUC, São Paulo, and an MBA from Loyola University Maryland. In the US, she worked as a Project Manager at Universal Dialog and a Marketing Manager at Zimmer Dental supporting international strategic marketing initiatives.

Scott Wulff is a Production Scientist at Becton Dickinson Diagnostic Systems, manufacturer of medical diagnostic instrumentation, located in Hunt Valley MD and a division of Becton Dickinson Co. (BD). Scott has a BS from Salisbury University, an MS in Biotechnology from Johns Hopkins University, and an MBA from Loyola University Maryland. He has worked at BD for 19 years both in R\&D and most recently in Operations investigating product quality issues and improving manufacturing efficiencies.

\section{REFERENCES}

1. __ (2006) Health care at the crossroads: Guiding principles for the development of the hospital of the future. Report of the Joint Commission on Accreditation of Health Care Organizations, pp. 1-45.

2. __ (2008) Hospital of the future: core concepts. Navigant Consulting, Inc. presentation, July 9, Silver Spring, MD. 
3. ___ a, (2009) Definition of facility management, International Facility Management Association, Retrieved from website: http://www.ifma.org/what_is_fm/index.cfm, Nov. 18.

4. _ _ b , (2009) White paper on strategic facility planning, International Facility Management Association, pp. $1-20$.

5. ___ c (2009) Community Hospital Replacement Study, Industry Report of Stroudwater Associates, pp. 140.

6. Glagola, J. R. (2002) An introduction to strategic facilities planning. Real Estate Issues, 27(1), pp. 13-15.

7. Keehan, S (2008) Health spending projections through 2017. Health Affairs Web Exclusive W146, 21 February 2008.

8. Porter, M. E., and Teisberg, E. O. (2004) Redefining competition in health care. Harvard Business Review, 82(6), pp. 64-76.

9. Reeve, J. R.,(2001) Strategic facility planning improves capital decision making. Healthcare Financial Management, pp. 35-38.

10. Shohet, I. M. (2006) Key performance indicators for strategic healthcare facilities maintenance. Journal of Construction Engineering and Management, April 2006, pp. 345-352.

11. Weitzner, W. M. (2006) 5 facility planning mistakes (and how to avoid them). Healthcare Financial Management, May 2006, pp. 94-100. 